\title{
Volatile Constituents and Antioxidant Activity of Peel, Flowers and Leaf Oils of Citrus aurantium L. Growing in Greece
}

\author{
Eirini Sarrou ${ }^{1, *}$, Paschalina Chatzopoulou ${ }^{2}$, Kortessa Dimassi-Theriou ${ }^{1}$ and Ioannis Therios ${ }^{1}$ \\ 1 Laboratory of Pomology, School of Horticulture, Aristotle University of Thessaloniki 54124, \\ Greece; E-Mails: dimassik@agro.auth.gr (K.D.-T.); therios@agro.auth.gr (I.T.) \\ 2 Hellenic Agricultural Organization - Demeter (former NAGREF), Department of Aromatic and \\ Medicinal Plants, Thessaloniki 57001, Greece; E-Mail: chatzopoulou@nagref.gr \\ * Author to whom correspondence should be addressed; E-Mail: irene_sr@windowslive.com; \\ Tel.: +30-2310-998-603; Fax: +30-2310-472-497.
}

Received: 24 June 2013; in revised form: 23 August 2013 / Accepted: 28 August 2013 /

Published: 2 September 2013

\begin{abstract}
The volatile constituents of the essential oils of the peel, flower (neroli) and leaves (petitgrain) of bitter orange (Citrus aurantium L.) growing in Greece were studied by GC-MS. The analytical procedures enabled the quantitative determination of 31 components. More specifically, the components of the essential oils identified were: twelve in the peel, twenty-six in the flowers, and twenty and sixteen in old and young leaves, respectively. The major constituents of the different parts of Citrus aurantium L. essential oils were: $\beta$-pinene $(0.62 \%-19.08 \%)$, limonene $(0.53 \%-94.67 \%)$, trans- $\beta$-ocimene $(3.11 \%-6.06 \%)$, linalool $(0.76 \%-58.21 \%)$, and $\alpha$-terpineol $(0.13 \%-12.89 \%)$. The DPPH test demonstrated that the essential oils in the old leaves had the maximum antioxidant activity, followed by the flowers, young leaves and the peel in that order. This study updates the data in the literature on the essential oils of bitter orange, and provides information on the composition of the oils for a further evaluation of this product.
\end{abstract}

Keywords: antioxidant activity; Citrus aurantium L.; essential oils composition; neroli; peel; petitgrain 


\section{Introduction}

Citrus aurantium L. (Rutaceae family), also known as sour orange or bitter orange, is generally used as a rootstock and has a number of advantages, including resistance to several viral diseases, tolerance to cold, improvement in the fruit quality of the grafted plants, and it can be used as an ornamental tree [1]. In addition, Citrus aurantium L. is among the species that have been used for medicinal purposes on account of the various bioactive compounds that it contains, such as phenolics, flavonoids, essential oils, and vitamins. The parts mostly used for medicinal purposes are the fruit peel, the flowers and the leaves of the plant [2]. Immature fruits are sometimes pickled or used as a condiment. The peel of $C$. aurantium L. contains limonene as the major essential oil constituent, flavonoids, hesperidin, neohesperidin, naringin and tangaretin and it is often used in marmalade production, whereas dried peel is used in bouquet garni and for flavoring the Belgian beer called Orange Muscat [3]. Essential oils from the dried peel of unriped Citrus aurantium L. fruits flavor drinks and liquors, like Curaçao, Cointreau, and Triple Sec. The flowers are used in teas, whereas the essential oil (neroli) is used in perfumes, liqueurs, and orange-flower water used to flavor sweets [4]. Besides the uses mentioned above, undiluted essential oils are sold at a high price on the international market of aromatherapy, perfume and cosmetic industry as well. Moreover, numerous studies have been reported on the assorted medical uses (antioxidant, antimicrobial, antifungal, antiparasitic, anti-inflammatory, etc.) of several $C$. aurantium essential oil constituents and other compounds isolated from peel [5-7]. Limonene and $\beta$-myrcene were reported as the major components of the peel oil while linalool, linalyl acetate and $\alpha$-terpineol predominate in the leaf oil (petitgrain) [8].

The aim of this study was the characterization of the essential oils from different parts (flowers, peel and leaves) of the Citrus aurantium L. trees growing in Northern Greece and to investigate their antioxidant activity. To our knowledge this is the first report on the essential oils obtained from different parts of Greek Citrus aurantium L.

\section{Results and Discussion}

\subsection{Essential Oil Composition}

A clear yellow volatile oil with a fresh sweet odor was obtained through the hydrodistillation of flowers, peel, young and old leaves of $C$. aurantium L. at $0.12 \%, 1.67 \%, 0.27 \%$ and $0.45 \%$ respectively ( $\mathrm{mL} / 100 \mathrm{~g}$ of fresh tissue). The chemical composition of the essential oils from different parts of C. aurantium L. was analyzed by GC-MS. Qualitative and quantitative analytical results are shown in Table 1.

In neroli oil twenty six constituents accounted for the $99.44 \%$ of the oil. The major compounds were linalool (29.14\%), $\beta$-pinene (19.08\%), limonene (12.04\%), trans- $\beta$-ocimene $(6.06 \%)$ and $E$-farnesol (5.14\%). Twenty components constituted $99.87 \%$ of the peel oil (Table 1). The main compounds were: limonene $(94.67 \%)$, myrcene $(2.00 \%)$, linalool $(0.76 \%), \beta$-pinene $(0.62 \%)$ and $\alpha$-pinene $(0.53 \%)$. 
Table 1. Essential oil content (\%) of flowers, peel, young and old leaf of Citrus aurantium L. and their main constituents.

\begin{tabular}{|c|c|c|c|c|c|c|c|}
\hline \multirow{2}{*}{$\mathbf{N r}$} & \multirow[t]{2}{*}{ Compounds ${ }^{a}$} & \multirow[t]{2}{*}{$R T^{\mathrm{b}}$} & \multirow[t]{2}{*}{ Retention Index } & \multicolumn{4}{|c|}{ Concentration \% ${ }^{\mathrm{d}, \mathrm{e}}$} \\
\hline & & & & Flowers & Peel & Young Leaves & Old Leaves \\
\hline 1 & $\alpha$-Pinene & 7.722 & 934 (939) & $1.35 \pm 0.01$ & $0.53 \pm 0.02$ & $0.19 \pm 0.00$ & - \\
\hline 2 & Sabinene & 9.542 & $973(976)$ & $2.01 \pm 0.20$ & $0.18 \pm 0.01$ & $0.37 \pm 0.00$ & $0.22 \pm 0.03$ \\
\hline 3 & $\beta$-Pinene & 9.750 & $980(980)$ & $19.08 \pm 0.18$ & $0.62 \pm 0.04$ & $3.58 \pm 0.01$ & $1.90 \pm 0.31$ \\
\hline 4 & Myrcene & 10.509 & 991 (991) & $1.59 \pm 0.01$ & $2.00 \pm 0.04$ & $1.63 \pm 0.06$ & $2.74 \pm 0.32$ \\
\hline 5 & Octanal & 10.953 & 999 (1001) & - & $0.24 \pm 0.01$ & - & - \\
\hline 6 & $3-\delta$-Carene & 11.816 & $1014(1011)$ & $0.17 \pm 0.00$ & - & - & - \\
\hline 7 & Limonene & 12.630 & $1029(1031)$ & $12.04 \pm 0.16$ & $94.67 \pm 0.01$ & $0.53 \pm 0.01$ & $0.77 \pm 0.09$ \\
\hline 8 & cis- $\beta$-Ocimene & 13.206 & $1039(1040)$ & $0.77 \pm 0.02$ & $0.30 \pm 0.01$ & $0.71 \pm 0.02$ & $1.22 \pm 0.07$ \\
\hline 9 & trans- $\beta$-Ocimene & 13.884 & $1049(1050)$ & $6.06 \pm 0.01$ & - & $4.08 \pm 0.05$ & $3.11 \pm 0.21$ \\
\hline 10 & $\gamma$-Terpinene & 14.550 & $1060(1062)$ & $0.36 \pm 0.01$ & - & - & - \\
\hline 11 & Linalool oxide & 15.353 & $1071(1074)$ & $0.29 \pm 0.02$ & - & - & - \\
\hline 12 & $\alpha$-Terpinolene & 16.440 & $1086(1088)$ & $0.47 \pm 0.01$ & - & $0.40 \pm 0.01$ & $0.70 \pm 0.04$ \\
\hline 13 & Linalool & 17.729 & $1102(1104)$ & $29.14 \pm 0.38$ & $0.76 \pm 0.04$ & $58.21 \pm 0.37$ & $36.03 \pm 0.60$ \\
\hline 14 & Terpin 4-ol & 23.122 & 1174 (1177) & $0.68 \pm 0.02$ & - & $0.17 \pm 0.01$ & $0.13 \pm 0.02$ \\
\hline 15 & $\alpha$-Terpineol & 24.267 & 1187 (1189) & $4.56 \pm 0.05$ & $0.13 \pm 0.01$ & $7.11 \pm 0.06$ & $12.89 \pm 0.37$ \\
\hline 16 & Decanal & 25.574 & $1202(1204)$ & - & $0.16 \pm 0.03$ & - & - \\
\hline 17 & Nerol & 27.489 & $1227(1228)$ & $0.83 \pm 0.02$ & - & $1.45 \pm 0.02$ & $2.89 \pm 0.06$ \\
\hline 18 & Geraniol & 29.864 & $1257(1255)$ & $4.31 \pm 1.43$ & - & - & - \\
\hline 19 & Linalyl acetate & 30.963 & $1259(1257)$ & $3.88 \pm 0.40$ & $0.18 \pm 0.03$ & $12.42 \pm 0.13$ & $23.00 \pm 1.42$ \\
\hline 20 & Methyl anthranylate & 36.245 & 1334 (1337) & $0.19 \pm 0.00$ & - & - & - \\
\hline 21 & $\delta$-Elemene & 36.458 & $1337(1339)$ & $0.12 \pm 0.00$ & - & - & - \\
\hline 22 & Terpinyl acetate & 37.426 & $1349(1350)$ & $0.20 \pm 0.00$ & - & - & $0.11 \pm 0.00$ \\
\hline 23 & Neryl acetate & 38.901 & $1368(1365)$ & $1.30 \pm 0.01$ & $0.10 \pm 0.00$ & $2.18 \pm 0.07$ & $4.46 \pm 0.22$ \\
\hline 24 & Geranyl acetate & 40.419 & $1386(1383)$ & $2.59 \pm 0.04$ & - & $4.49 \pm 0.11$ & $8.70 \pm 0.37$ \\
\hline 25 & $\beta$-Caryophyllene & 42.266 & $1412(1418)$ & $0.42 \pm 0.01$ & - & $1.09 \pm 0.02$ & $0.22 \pm 0.01$ \\
\hline 26 & $\alpha$-Humulene & 44.268 & $1447(1454)$ & - & - & $0.10 \pm 0.00$ & - \\
\hline 27 & (E)- $\beta$-Farnesene & 44913 & $1458(1458)$ & - & - & $0.13 \pm 0.01$ & - \\
\hline 28 & $\delta$-Germacrene & 45.948 & $1476(1480)$ & $0.13 \pm 0.01$ & - & - & - \\
\hline 29 & Bicyclogermacrene & 46.764 & 1489 (1494) & - & - & $0.18 \pm 0.00$ & $0.20 \pm 0.01$ \\
\hline 30 & (E)-Nerolidol & 50.451 & $1566(1564)$ & $1.76 \pm 0.03$ & - & - & $0.10 \pm 0.00$ \\
\hline 31 & $(E)$-Farnesol & 55.544 & $1725(1722)$ & $5.14 \pm 0.02$ & - & - & - \\
\hline \multicolumn{3}{|c|}{ Total percentage $^{\mathrm{d}}$} & & $99.44 \%$ & $99.87 \%$ & $99.02 \%$ & $99.39 \%$ \\
\hline \multicolumn{3}{|c|}{ Essential oil (\%) content } & & $0.12 \pm 0.01$ & $1.67 \pm 0.07$ & $0.27 \pm 0.01$ & $0.45 \pm 0.02$ \\
\hline
\end{tabular}

${ }^{\mathrm{a}, \mathrm{b}}$ order of elution on DB-5 column, RT: retention time; ${ }^{\mathrm{c}}$ Calculated relative to C7-C40 n-alcanes, on DB-5 column. In parentheses, Literature Retention Indices on similar column; ${ }^{\mathrm{d}}$ Percentage of the total peak area. Components with percentage $\geq 0.1 \%$ are presented; ${ }^{\mathrm{e}}: \pm$ St error.

The qualitative composition of both petitgrain oils (obtained from young and old leaves) was similar. Sixteen compounds were common, among which the major components were: linalool (58.21\%-36.03\%), $\alpha$-terpineol $(7.11 \%-12.89 \%)$, geranyl acetate $(4.49 \%-8.70 \%)$, neryl acetate $(2.18 \%-4.46 \%)$ and trans- $\beta$-ocimene $(4.08 \%-3.11 \%)$. $\alpha$-Pinene, $\alpha$-humulene and $(E)-\beta$-farnesene 
(amounting to $0.42 \%$ ) were detected only in the young leaf oil, whereas terpinyl acetate and nerolidol E (cumulative $0.21 \%$ ) were detected in the old leaf oil.

There were significant differences in the qualitative and quantitative composition of the examined oils. Peel oil is composed almost of monoterpene hydrocarbons (98.30\%), mainly limonene, while oxygenated monoterpenes are dominant compounds of leaf and flowers oils, detected at higher amounts in old leaves (88.09\%) (Figure 1a). The amount of sesquiterpenes in neroli oil (7.67\%) differed significantly from petitgrain oils, while in the peel oil they were not detected at all (Figure 1b).

Figure 1. (a) \% yield of monoterpene hydrocarbons, oxygenated monoterpenes and (b) sesquiterpenes, in the oils from different parts of Citrus aurantium L. Vertical bars represent means $(n=3) \pm S E$. Different letters indicate a significant difference at $p \leq 0.05$.

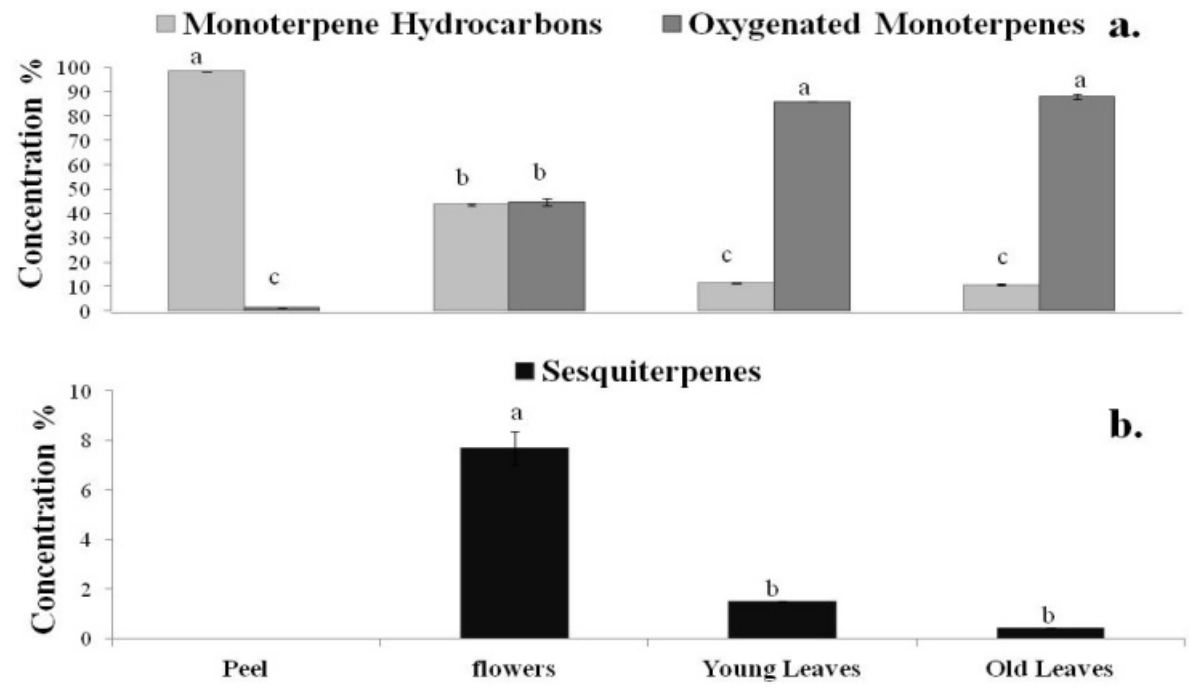

Several studies on the chemical composition of the essential oils extracted from C. aurantium L. seem to be in agreement with our findings, indicating that the main components of peel oil are monoterpene hydrocarbons like limonene and myrcene, while those of petitgrain oil are linalool, linalyl acetate, geranyl acetate and $\alpha$-terpineol [8-13]; and neroli oil contained linalool, limonene and linalyl acetate [14-16]. Limonene, estimated at 96.7\%, was also the main component of $C$. aurantium peel oil from Greece [17]. Quantitative differences may arise due to different genotype, the pedoclimatic conditions in the growing areas, etc.

\subsection{DPPH Radical Scavenging Activity}

The ability of the essential oils to act as hydrogen or electron donors in the transformation of DPPH into its reduced form DPPH-H was investigated. The antioxidant activities of all the oils tested are presented in Figure 2. All the essential oils were able to reduce the stable, purple-colored radical DPPH to the yellow-colored DPPH-H. The scavenging activity of flowers, young leaves and peel oil was determined at $53.98 \%, 22.79 \%$ and $19.29 \%$, respectively. The oil of the old leaves showed the highest scavenging activity (94.36\%). This could be due to water losses of the older leaves which affects the accumulation of the secondary metabolites through the reallocation of the assimilated carbon as leaf growth is progressively reduced. Another possible explanation is that some components of the above oils contribute differently to the antioxidant activity. 
Figure 2. DPPH scavenging activity of the essential oils obtained from peel, flowers, young and old leaves. Vertical bars represent means $(n=3) \pm$ SE. Different letters indicate a significant difference at $p \leq 0.05$.

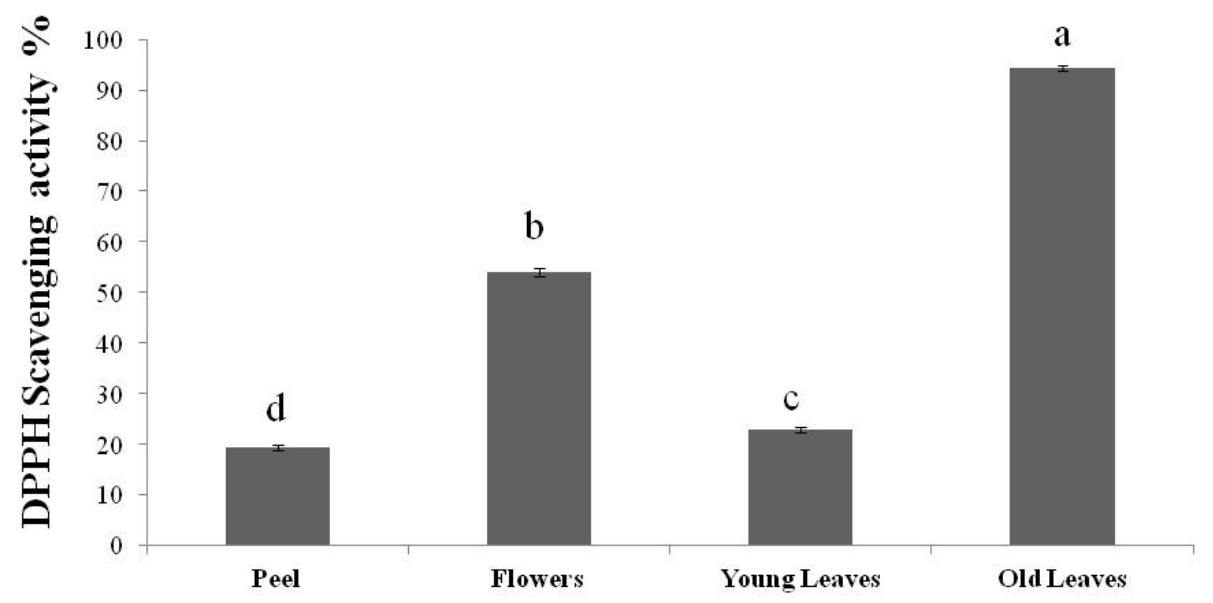

Several studies on the chemical composition and bioactivity of different citrus oils reported strong radical scavenging activity [18-21]. It is suggested that, even at low concentrations, authentic flavor components such as $\gamma$-terpinene, terpinolene, geraniol, $\beta$-pinene and myrcene have high antioxidant activities [7,22]. Choi et al. found that the radical scavenging activity of 34 kinds of citrus essential oils on DPPH ranged from $17.7 \%$ to $64 \%$. These activities were found to be higher when the oils contained geraniol, terpinolene and $\gamma$-terpinene [7]. The fact that the essential oil of old leaves and flowers had the highest scavenging activity, may be due to the presence of $\alpha$-terpinolene and nerol in petitgrain oil and $\gamma$-terpinene, nerol and geraniol in the neroli oil [7,22]. Nevertheless, further studies are needed to evaluate the scavenging effects of the authentic compounds of $C$. aurantium essential oils. However, the bioactivity of the essential oils generally results from a complex interaction between its constituents, which produce both synergistic and antagonistic responses [23].

\section{Experimental}

\subsection{Chemicals}

The $n$-alkanes $\left(\mathrm{C}_{7}-\mathrm{C}_{40}\right)$ was purchased from Supelco (Bellefonte, PA, USA). Anhydrous sodium sulphate $\left(\mathrm{Na}_{2} \mathrm{SO}_{4}\right)$ and 2.2-diphenyl-1-picrylhydrazyl (DPPH) used were purchased from Roth and Sigma-Aldrich (Steinheim, Germany). The highest purity pentane used for the GC-MS was purchased from Panreac Quimica S.L.U (Barcelona, Spain).

\subsection{Plant Material}

Different parts of mature Citrus aurantium L. trees were collected from the same orchard, in Thessaloniki, Greece, (40³4'35" N 2257'19" E), 2011. At the beginning of April, young leaves (up to the 3 rd node from the top of the shoots) and old leaves (from the basal parts of the shoots) were gathered between 11:00-12:00 in the morning and they were then cut in half. At the same time the flowers were also picked. The fresh fruits, on the other hand, were collected at the beginning of October. As soon as each part was gathered, it was immediately subjected to hydrodistillation. 


\subsection{Determination of Essential Oils}

The essential oil content was determined using the European Pharmacopoeia apparatus (Clevenger-type). The various parts of Citrus aurantium L. were subjected to hydrodistillation as follows: the fresh leaves for $4 \mathrm{~h}$, the flowers for $3 \mathrm{~h}$, and the peel also for $3 \mathrm{~h}$, with a distillation rate 3 to $3.5 \mathrm{~mL} / \mathrm{min}$. Hydrodistilled fresh mass was $60 \mathrm{~g}$ for the leaves, $150 \mathrm{~g}$ and $35 \mathrm{~g}$ for the flowers and the peel respectively. The oil yields were estimated on the basis of the wet weight plant material $(\mathrm{mL} / 100 \mathrm{~g})$. The obtained essential oils were then dried over anhydrous sodium sulphate and stored at $4-6{ }^{\circ} \mathrm{C}$.

\subsection{GC-MS Analysis}

The GC-MS analysis was performed on a DB-5 column, using a Gas Chromatograph Shimadzu GC-17A interfaced with a Mass Spectrometer Shimadzu QP-5050A supported by the Class 5000 software. Injection temperature: $260{ }^{\circ} \mathrm{C}$, interface heating: $300{ }^{\circ} \mathrm{C}$, ion source heating: $200{ }^{\circ} \mathrm{C}$, EI mode: $70 \mathrm{eV}$, scan range: $41-450 \mathrm{amu}$, and scan time $0.50 \mathrm{~s}$. Oven temperature programs: (a) $55-120^{\circ} \mathrm{C}$ $\left(3{ }^{\circ} \mathrm{C} / \mathrm{min}\right), 120-200{ }^{\circ} \mathrm{C}\left(4{ }^{\circ} \mathrm{C} / \mathrm{min}\right), 200-220{ }^{\circ} \mathrm{C}\left(6{ }^{\circ} \mathrm{C} / \mathrm{min}\right)$ and $220{ }^{\circ} \mathrm{C}$ for $5 \mathrm{~min}$ and (b) $60-240{ }^{\circ} \mathrm{C}$ at $3{ }^{\circ} \mathrm{C} / \mathrm{min}$, carrier gas $\mathrm{He}, 54.8 \mathrm{kPa}$, split ratio $1: 30$. The relative content of each compound was calculated as percent of the total chromatographic area and the results are expressed as means of triplicate experiments.

\subsection{Identification of Components}

The identification of the components was based on comparison of their retention indices (RI) relative to $n$-alkanes $\left(\mathrm{C}_{7}-\mathrm{C}_{40}\right)$, with corresponding literature data [24-26] as well by matching (a) their spectra with those from MS libraries (NIST 98, Willey, Adams 1995) [26] and (b) the retention time (RT) of co-eluting reference compounds-peak enrichment technique (authentic samples obtained from Roth and Sigma Aldrich).

\subsection{DPPH Radical Scavenging Activity Assay}

Total antioxidant activity was determined following the method of $\mathrm{Su}$ et al. [27]. Fifty $\mu \mathrm{L}$ of essential oils (100\% concentration) added to $0.1 \mathrm{mM} \mathrm{DPPH}$ solution $(2.95 \mathrm{~mL})$. After $1 \mathrm{~h}$ the absorbance of the reaction mixture was measured in triplicate at $517 \mathrm{~nm}$ on a spectrophotometer (Prim, SECOMAM, Domont, France). The control solution was prepared by adding absolute ethanol $(50 \mu \mathrm{L})$ to the DPPH solution and ethanol was used as a blank. Measurements were expressed as scavenging activity $\%$. The antioxidant activity was determined by the following formula:

$$
\text { Scavenging Activity }(\%)=\{(\text { Abs control }- \text { Abs sample }) / \text { Abs control }\} \times 100
$$

where Abs is the absorbance at $517 \mathrm{~nm}$.

\subsection{Statistical Analysis}

All samples were analyzed in triplicate and the results are expressed as the means. The data were analysed with Analysis of Variance (ANOVA), using the statistical package SPSS 17.0 (SPSS Inc., 
Chicago, IL, USA). For mean comparison, the Duncan's multiple range test and standard error (S.E) were used at $p \leq 0.05$ to establish significant differences.

\section{Conclusions}

In conclusion, our study indicated that Greek Citrus aurantium L. essential oils are a potential natural source of monoterpenes such as limonene, $\beta$-pinene, linalool and linalyl acetate. In addition, as a result of the scavenging effects, it is expected that citrus essential oils and the related flavor components may contribute to the prevention of oxidation as antioxidants and free radical scavengers. This research may be of interest from a functional point of view and for the valorization of Citrus aurantium L. in Greece and the wider Mediterranean region.

\section{Acknowledgments}

This work was supported financially by the Aristotle University of Thessaloniki. We would also like to express our sincere thanks to Sofia Kuti, Vasiliki Tsakiridou and Eleni Lalidou for technical assistance.

\section{Conflicts of Interest}

The authors declare no conflict of interest.

\section{References}

1. Al-Ababneh, S.S.; Karam, N.S.; Shibli, R.A. Cryopreservation of sour orange (Citrus aurantium L.) shoot tips. In Vitro Cell. Dev. Biol. Plant 2002, 38, 602-607.

2. Moraes, T.M.; Kushima, H.; Moleiro, F.C.; Santos, R.C.; Machado Rocha, L.R.; Marques, M.O.; Vilegas, W.; Hiruma-Lima, C.A. Effects of limonene and essential oil from (Citrus aurantium) on gastric mucosa: Role of prostaglandins and gastric mucus secretion. Chem. Biol. Interact. 2009, 180, 499-505.

3. Kiple, K.F.; Ornelas, K.C. The Cambridge World History of Food; Cambridge University Press: Cambridge, UK, 2000; pp. 1822-1826.

4. Fugh-Berman, A.; Myers, A. Citrus aurantium, an ingredient of dietary supplements marketed for weight loss: Current status of clinical and basic research. Exp. Biol. Med. 2004, 229, 698-704.

5. Wei, A.; Shibamoto, T. Antioxidant/lipoxygenase inhibitory activities and chemical compositions of selected essential oils. J. Agric. Food Chem. 2010, 58, 7218-7225.

6. Ramadan, W.; Mourad, B.; Ibrahim, S.; Sonbol, F. Oil of bitter orange: New topical antifungal agent. Int. J. Dermatol. 1996, 35, 448-449.

7. Sonbol, F.; Ibrahim, S.M.; Mohamed, B.M. Antimicrobial activity of oil of bitter orange. Alex. J. Pharm. Sci. 1992, 9, 107-109.

8. Choi, H.S.; Song, H.S.; Ukeda, H.; Sawamura, M. Radical-scavenging activities of citrus essential oils and their components: Detection using 1, 1-diphenyl-2-picrylhydrazyl. J. Agric. Food Chem. 2000, 48, 4156-4161. 
9. Azadi, B.; Nickavar, B.; Amin, G. Volatile constituents of the peel and leaf of Citrus aurantium L. cultivated in the north of Iran. J. Pharm. Health Sci. 2012, 1, 37-41.

10. Njoroge, S.M.; Ukeda, H.; Kusunose, H.; Sawamura, M. Volatile components of the essential oils from kabosu, daidai, and yuko, Japanese sour Citrus fruits. Flavour Fragr. J. 1994, 9, 289-297.

11. Dugo, P.; Mondello, L.; Cogliandro, E.; Verzera, A.; Dugo, G. On the genuineness of citrus essential oils. 51. Oxygen heterocyclic compounds of bitter orange oil (Citrus aurantium L.). J. Agric. Food Chem. 1996, 44, 544-549.

12. Lota, M.L.; de Rocca Serra, D.; Jacquemond, C.; Tomi, F.; Casanova, J. Chemical variability of peel and leaf essential oils of sour orange. Flavour Fragr. J. 2001, 16, 89-96.

13. Kirbaşlar, F.G.; Tavman, A.; Dülger, B.; Türker, G. Antimicrobial activity of Turkish Citrus peel oils. Pak. J. Bot. 2009, 41, 3207-3212.

14. Hosni, K.; Zahed, N.; Chrif, R.; Abid, I.; Medfei, W.; Kallel, M.; Ben Brahim, N.; Sebei, H. Composition of peel essential oils from four selected Tunisian Citrus species: Evidence for the genotypic influence. Food Chem. 2010, 123, 1098-1104.

15. Monsef-Esfahani, H.R.; Amanzade, Y.; Alhani, Z.; Hajimehdipour, H.; Faramarzi, M.A. GC/MS analysis of Citrus aurantium L. Hydrolate and its comparison with the commercial samples. Iran. J. Pharm. Res. 2004, 3, 177-179.

16. Boussaada, O.; Chemli, R. Chemical composition of essential oils from flowers, leaves and peel of Citrus aurantium L. var. amara from Tunisia. J. Essent. Oil Bear. Plants 2006, 9, 133-139.

17. Hérent, M.F.; De Bie, V.; Tilquin, B. Determination of new retention indices for quick identification of essential oils compounds. J. Pharm. Biomed. Anal. 2007, 43, 886-892.

18. Seok, B.J.; Kim, S.S.; Lee, J.A.; Oh, T.H.; Kim, J.Y.; Lee, N.H.; Hyun, C.G. Chemical composition and biological activities of essential oils extracted from Korean Endemic Citrus Species. J. Microbiol. Biotechnol. 2008, 18, 74-79.

19. Malhotra, S.; Suri, S.; Tuli, R. Antioxidant activity of citrus cultivars and chemical composition of Citrus karna essential oil. Planta Med. 2009, 75, 62-64.

20. Hamdan, D.; El-Readi, M.Z.; Nibret, E.; Sporer, F.; Farrag, N.; El-Shazly, A.; Wink, M. Chemical composition of the essential oils of two Citrus species and their biological activities. Pharmazie 2010, 65, 141-147.

21. Singh, P.; Shukla, R.; Prakash, B.; Kumar, A.; Singh, S.; Kumar Mishra, P.; Dubey, N.K. Chemical profile, antifungal, antiaflatoxigenic and antioxidant activity of Citrus maxima Burm. and Citrus sinensis (L.) Osbeck essential oils and their cyclic monoterpene, DL-limonene. Food Chem. Toxicol. 2010, 48, 1734-1740.

22. Song, H.S.; Ukeda, H.; Sawamura, M. Antioxidative activities of Citrus peel essential oils and their components against linoleic acid oxidation. Food Sci. Technol. Res. 2001, 7, 50-56.

23. Tundis, R.; Loizzo, M.R.; Bonesi, M.; Menichini, F.; Mastellone, V.; Colica, C.; Menichini, F. Comparative study on the antioxidant capacity and cholinesterase inhibitory activity of Citrus aurantifolia Swingle, C. aurantium L., and C. bergamia Risso and Poit. Peel essential oils. J. Food Sci. 2012, 77, 40-46.

24. De Pasquale, F.; Siragusa, M.; Abbate, L.; Tusa, N.; De Pasquale, C.; Alonzo G. Characterization of five sour orange clones through molecular markers and leaf essential oils analysis. Sci. Hortic. 2006, 109, 54-59. 
25. Kamal, G.M.; Anwar, F.; Hussain, A.I.; Sarri, N.; Ashraf, M.Y. Yield and chemical composition of Citrus essential oils as affected by drying pretreatment of peels. Int. Food Res. J. 2011, 18, 1275-1282.

26. Adams, R.P. Identification of Essential Oil Components by Gas Chromatography/Mass Spectroscopy; Allured Publishing Co.: Carol Stream, IL, USA, 1995.

27. $\mathrm{Su}, \mathrm{M}$; Silva, J.L. Antioxidant activity, anthocyanins and phenolics of rabbiteye blueberry (Vaccinium ashei) byproducts as affected by fermentation. Food Chem. 2006, 97, 447-451.

Sample Availability: Samples of the essential oils are available from the authors.

(C) 2013 by the authors; licensee MDPI, Basel, Switzerland. This article is an open access article distributed under the terms and conditions of the Creative Commons Attribution license (http://creativecommons.org/licenses/by/3.0/). 